\title{
Adverse drug reaction management in hospital settings: review on practice variations, quality indicators and education focus
}

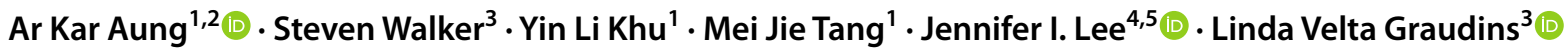

Received: 28 September 2021 / Accepted: 31 January 2022 / Published online: 16 February 2022

(c) Crown 2022

\begin{abstract}
Purpose Adverse drug reactions (ADRs) contribute significantly to healthcare burden. However, they are largely preventable through appropriate management processes. This narrative review aims to identify the quality indicators that should be considered for routine monitoring of processes within hospital ADR management systems. It also examines the potential reasons behind variation in ADR management practices amongst HCPs, and explores possible solutions, focusing on targeted education programmes, to improve both the quality and quantity indicators of ADR management processes.

Methods A comprehensive literature review was conducted to explore relevant themes and topics concerning ADR management, quality indicators and educational interventions.

Results Substantial variability exists in ADR management amongst healthcare professionals (HCPs) with regard to reporting rates, characteristics of ADRs reported, quality of assessment, completeness of reports and, most importantly, risk communication practices. These variable practices not only threaten patient safety but also undermine pharmacovigilance processes. To date, quality indicators to monitor ADR management practices within hospital settings remain ill-defined. Furthermore, evidence behind effective interventions, especially in the form of targeted education strategies, to improve the quality of ADR management remains limited.

Conclusions The focus of ADR management in hospitals should be to promote patient safety through comprehensive assessment, risk communication and safe prescribing. There is a need to develop a system to define, measure and monitor the quality of ADR management. Educational strategies may help improve the quality of ADR management processes.
\end{abstract}

Keywords Adverse drug reactions $\cdot$ Reporting $\cdot$ Management $\cdot$ Quality $\cdot$ Practice variations $\cdot$ Education strategies

\section{Introduction}

Adverse drug reactions (ADRs) are defined as a 'response to a medicinal product which is noxious and unintended, which occurs at doses normally used in man' and specifically denote reactions caused by the pharmacological action of the medication itself, rather than as a result of incorrect use [1]. ADRs are commonly categorised by Rawlins' classification system into type A or type B reactions, and less commonly to other types, according to underlying pathogen-

\section{Key points}

- Substantial variability exists in ADR management processes amongst healthcare workers and in different healthcare settings

- Quality indicators to monitor ADR management practices remain ill-defined in hospital settings.

- Targeted education programmes may improve both the quality and quantity of ADR management processes; however, in light of limited available evidence, more research is needed to examine which educational interventions would result in sustained improvement.

Ar Kar Aung

A.Aung@alfred.org.au
1 Department of General Medicine, Alfred Hospital, Melbourne, Australia

2 School of Public Health and Preventive Medicine, Monash University, Melbourne, Australia

3 Department of Pharmacy, Alfred Hospital, Melbourne, Australia

4 Department of Medicine, NewYork-Presbyterian Hospital/Weill Cornell Medicine, New York, USA

5 Quality Improvement Academy, Weill Cornell Medicine, New York, USA 
Table 1 Rawlins' classification system of adverse drug reactions [23]

\begin{tabular}{lll}
\hline Type & Underlying pathophysiology and characteristics & Examples \\
\hline A & Augmented pharmacological effects through PK and PD, predictable & Hypotension from calcium channel blockers \\
B & Bizarre effects, frequently due to immune-mediated mechanisms, not related to & Anaphylaxis to penicillins \\
& PK/PD properties, unpredictable & Toxic epidermal necrolysis to carbamazepine \\
C & Long term effects related to dose and duration of administration & Adrenal suppression from prolonged prednisolone use \\
D & Long term effects resulting in carcinogenesis, teratogenesis or chronic organ & Cyclophosphamide and bladder cancer \\
& damage & Amiodarone and pulmonary fibrosis \\
E & Effects related to withdrawal & Opiate withdrawal \\
F & Therapeutic effects or failure due to drug interactions & Bone marrow suppression related to concurrent \\
& & methotrexate and trimethoprim/sulfamethoxazole \\
& & administration
\end{tabular}

$P D$ pharmacodynamics, $P K$ pharmacokinetics

esis and clinical attributes (Table 1) [2]. Preventable ADRs are those that are caused by administration errors, such as incorrect medication/dose/timing, prescription to a patient with a known allergy and inadequate monitoring [3]. Pharmacovigilance is an overarching term in ADR terminology, which encompasses safety activities and systems related to the detection, assessment, understanding and prevention of adverse effects or medication-related problems. Pharmacovigilance integrates identification of ADRs, data collection and analysis and regulatory activities as an integral part of any public health programme [4].

ADRs frequently occur in healthcare settings, contributing 3-5\% of hospital admissions in both adult and paediatric populations [5-9]. Approximately $10-17 \%$ of hospitalised patients experience an ADR [6, 10]. An episode of ADRrelated hospitalisation in itself is a risk factor for repeat hospitalisation due to another ADR [11]. ADR-affected patients carry a mortality risk of $10.7 \%$, nearly 3 -fold higher than those unaffected. A two-fold increase in length of hospital stay of up to 20 days can also result from ADR episodes [12]. In severe or life-threatening reactions, patients may suffer from substantial physical and psychological health impacts long-term [13, 14]. Overall, ADRs contribute in excess of 30 billion dollars to healthcare costs in the United States annually [8]. In Australia, the annual cost of medicationrelated admissions has also been estimated at AU\$ 1.2 billion, yet $45 \%$ of ADR-related hospitalisations may be prevented using appropriate measures $[9,15]$.

In various healthcare settings, including hospitals, ADR episodes are assessed and reported to pharmacovigilance authorities by healthcare professionals (HCPs) including medical doctors, pharmacists and nurses $[16,17]$. The reporting practices are usually voluntary, also termed 'spontaneous reporting'. This approach has been shown to be a cost-effective method to detect new and important ADR signals [18].

Many guidelines exist to increase awareness amongst HCPs of the burden of ADRs and highlight their moral and professional obligation to report ADR episodes, so as to reduce medication-related mortality and morbidity. One such document- the World Health Organisation's 'Safety of Medicines' guide_-provides generic recommendations for monitoring, assessment, reporting and education of ADRs, applicable to all healthcare settings in all countries [5]. Specific national guidelines also exist to guide pharmacovigilance activities in various healthcare settings. In Australia, the Therapeutics Goods Administration (TGA) requires reporting of all suspected adverse events to new therapeutic goods, all suspected medicine/vaccine interactions, unexpected adverse events to known medications that have not been previously described or serious adverse events defined as those resulting in death or disability [19].

Despite these well-intended guidelines, several aspects of ADR management remain heavily reliant on human factors, resulting in large variations in clinical practices. HCPs' attitudes have been known to influence suboptimal reporting rates [20]. The types of ADR reported and accuracy and completeness of reports are also known to vary depending on HCPs' experience and settings [21]. The process of ADR evaluation requires certain technical skills, such as basic understanding of pharmacologic and immunologic principles, comprehensive history taking, accurate assessment of medication exposure timelines, diagnostic investigations and consideration of alternative causes [5]. Where an ADR occurs in complex clinical settings, inaccurate assessment and reporting can cause harm through not recognising the culprit medication, whilst implication of wrong or by-stander medications may lead to unnecessary avoidance. Inaccurate evaluation also impacts post-marketing pharmacovigilance and undermines consumer confidence in medication safety.

Therefore, within each hospital, it is important to establish an ADR management system and then to regularly monitor indicators that enable benchmarking. Maintaining the quality of ADR processes reduces variations in practice and may ultimately improve patient safety. Pos- 
sible indicators include monitoring of ADR reporting rates and characteristics of medications and reactions, as well as ensuring that reports meet a certain standard. In reality, although the quantitative aspects of ADR reporting can be easily evaluated, quality parameters are harder to define or measure. The quality of an ADR report is a good reflection of HCPs' skills in assessing an ADR episode, which includes a minimum dataset of clinical information to enable evaluation of causality association between a medication and a reaction [22]. A quality report is largely influenced by technical ability, knowledge and experience, coupled with the awareness of imprecise science behind causality assessment. Furthermore, effective documentation and communication of risks to patients and other HCPs regarding an ADR episode also constitute an important quality measure.

In the context above, this narrative review attempts to highlight the key processes and outcomes that should be routinely considered as quality indicators in ADR management systems, specifically in hospital settings, by exploring the current literature on ADR assessment and reporting practices. It also provides an understanding of potential reasons for sources of variation in ADR management. Furthermore, it explores possible solutions, focusing on targeted education programmes, to improve both the quantity and quality indicators of ADR management processes.

\section{Variations in ADR management}

\section{ADR reporting rates}

Despite the cost-effectiveness of spontaneous reporting, under-reporting of ADRs by HCPs remains a global issue. Following the introduction of a spontaneous ADR reporting system in the UK in the early 1990s, it was estimated that only $10 \%$ or less of all ADRs were formally reported [23]. Moreover, a systematic review by Hazell et al. confirmed under-reporting rates to be as high as $94 \%$ with spontaneous reporting practices, when compared to the actual occurrence rates of known, suspected or expected ADR as determined through hospital or general practice-based monitoring systems [24]. Under-reporting rates in excess of 95\% also appeared to be similar between hospital and community settings [24].

Concerningly, the reporting rate for severe or life-threatening hypersensitivity reactions also remains low. A Canadian study found that out of a total 674 episodes of toxic epidermal necrolysis (TEN) cases nationally over a 6-year period, only 4\% were reported to the Canadian Adverse Drug Reaction Monitoring Program [25]. In an Australian context, a single-centre study of 81 patients with severe cuta- neous adverse drug reactions found that only $71.6 \%$ of cases had ADR reports submitted [26]. Amongst 80 patients with anaphylaxis reactions to non-antimicrobial medications, a large proportion of which were due to neuromuscular blocking agents in the perioperative setting; less than half (47.5\%) of the cases were reported for further evaluation [27]. Similarly, in a multicentre Australian study concerning antimicrobial-related anaphylaxis episodes, only $43.7 \%$ of 222 episodes were reported to ADR management systems within respective hospitals [28].

\section{Characteristics of ADR reports}

The type and characteristics of ADRs reported are also known to differ between professions, clinical expertise, practice settings, medication types and country of origin.

For instance, a Norwegian study found that pharmacists were more likely to report ADRs related to cardiovascular, gastrointestinal, metabolic and respiratory systems, whilst physicians were more likely to report ADRs related to musculoskeletal, anti-neoplastic and immunomodulating medications [17]. A similar study in the Netherlands, predominantly involving community pharmacists, found that pharmacists reported ADRs related to skin and eyes, whereas physicians tended to report ADRs related to cardiovascular system, liver dysfunction and psychiatric disorders [16]. Such reporting biases were likely influenced by the clinicians' expertise, types of patients seen and ADR manifestations encountered in different clinical settings. Additionally, differences in ADR definitions, reporting requirements, thresholds and target medications (e.g. biologics) to be reported, as determined by national pharmacovigilance authorities, may also contribute significantly to variations in certain types of ADRs preferentially reported by HCPs.

In terms of the nature of reactions, an Australian study found that of $555 \mathrm{ADR}$ reactions over a 2-year period, HCPs preferentially reported a higher number of immunologically mediated (Type B) reactions than pharmacologically related Type A reactions $(73.7 \%$ vs. $23.1 \%)$, perhaps reflecting a biased perception that Type B reactions were more harmful to patients [21]. The majority of reactions reported (>70\%) were of at least moderate severity. The time to assessment and reporting of severe cutaneous adverse reactions (i.e. drug rash/reaction with eosinophilia and systemic symptoms (DRESS), Stevens-Johnson syndrome/toxic epidermal necrolysis (SJS/TEN), acute generalised exanthematous pustulosis (AGEP)) was also longer compared to other reaction types, with a median reporting time of 12 days from onset of symptoms (IQR 5-18.5), further highlighting the intrinsic challenges and complexities associated with the assessment of these severe reactions. 


\section{Quality of ADR reports}

The quality and completeness of an ADR report refer to the minimum dataset required to determine causality [22]. Concise and accurate information regarding an ADR episode, including relevant clinical narrative and medications timeline, is helpful in identifying culprit medications and verifying the strength of causality. A careful and meticulous causality assessment is of utmost importance where multiple medications are involved. Tools such as Adverse Drug Reaction Probability Scale (also known as Naranjo algorithm) [29], Algorithm for Assessment of Drug Causality in Stevens-Johnson Syndrome and Toxic Epidermal Necrolysis (ALDEN) [30] and the Registry of Severe Cutaneous Adverse Reaction (Regi-SCAR) criteria [31] may also aid in clarifying the strength of causality in certain ADR conditions. However, these causality assessment tools have significant limitations, and new tools are being developed to provide better sensitivity and specificity in evaluation [32].

Data requirements for ADR reports are not uniform across the board. A multinational study by Bandekar et al. noted concerning variations and discrepancies in reporting forms between countries, with incomplete information, which may potentially lead to delayed recognition and withdrawal of medicines with unacceptable safety profiles by the regulatory authorities in the post-marketing phase [33]. The authors suggested that, ultimately, standardised ADR reporting methods across the board would provide a more complete, comparable and reliable dataset to allow timely recognition of important ADR signals [33, 34].

To assess the completeness of an ADR report, the Uppsala Monitoring Centre developed 'vigiGrade score'. This uses weighted input scores to assess completeness of information in the following domains: medication, dose, timeto-onset of ADR from medication initiation, indications for treatment, outcome of ADR, patient's gender and age, country of origin, occupation of reporter, type of report (spontaneous vs. clinical study) and free-text comments [22]. A weighted penalty score is applied to missing or incomplete information dimension. Although the vigiGrade score provides a validated method to evaluate the completeness of ADR reports, its complexity is a limitation to practical application outside a research setting. Furthermore, as the vigiGrade score focuses on data dimensions, rather than individual data elements, certain aspects of the score remain counter-intuitive in determining causality (for instance, no penalty score is applied to an implicated medication being commenced after the onset of a reaction).

Amongst those that utilised the vigiGrade score to evaluate completeness, the Catalan Center of Pharmacovigilance in Spain found that of 824 reports describing serious ADRs, the rate of incomplete information ranged from 7.9 to $50.1 \%$, with the information regarding 'time-to-onset' commonly missing in $17.5 \%$ [35]. Similarly, another Spanish study showed overall completion rate of $88 \%$ on the vigiGrade score for spontaneous ADR reports [36]. A Japanese study, which evaluated over 8000 reports from medical institutions, found that $75.6 \%$ were 'well documented' on the vigiGrade criteria, but 'time-to-onset' of reactions could not be determined in $14.9 \%$ of cases [37].

In studies using alternative systems of assessment, varying degrees of completeness and quality of information were evident. A Chinese study requiring 65 data items in their ADR reports found that only $10.18 \%$ of 3429 reports submitted to a regional pharmacovigilance centre were considered high quality [38]. Another study from a western Chinese pharmacovigilance centre with similar methodology found that of 1139 reports, only $1.4 \%$ were considered high quality [39]. Furthermore, a study on 999 ADR reports in Brazil noted that only $4.4 \%$ were sufficiently completed for causality assessment, whilst the completion rate was not influenced by severity or whether the reaction was well-known [40]. A French study, which assessed completeness based on extended information (e.g. co-morbidities, use of concomitant medications, diagnosis of effects, clinical course, outcome, therapeutic measures, laboratory data and response to de-challenge or re-challenge), in addition to the standard domains, found only $12.7 \%$ of the 613 ADR reports submitted by general practitioners to the regional pharmacovigilance centre were 'well-documented' [41]. On the other hand, several studies from Sweden, the Netherlands, Norway and India have reported high quality documentation rates of between 48 and nearly $100 \%$, in both community and hospital settings [16, 42-44].

All-in-all, these studies highlighted that quality assessment methods, and hence the quality and completeness of ADR reports, varied widely between centres and settings. The use of differing assessment criteria in these studies also made direct comparison challenging. There were no obvious factors that reliably explained why the quality of documentation varied widely between different centres and geographical regions.

\section{Risk communication}

Risk communication, whereby HCPs communicate regarding an ADR episode in a written/verbal form to patient, family and other health practitioners, is an important aspect of ADR management. The key goal is to provide specific information to eliminate or minimise re-exposure to the offending and structurally related medications [45]. Examples of risk communication include a medication alert card/bracelet for the patient and a concise hospital discharge summary. ADR alerts must also be entered into the patient's hospital medical records. Where causal medications are still undetermined at the time of patient 
review in the community or at hospital discharge, and/or where further assessment by a specialist is warranted, an interim advice to avoid suspected medications must also be provided.

To date, risk communication practices by HCPs have not been widely studied.

Teo et al. studied hospitalised patients with cutaneous adverse drug reactions, finding only 1 in 5 discharge summaries included the reaction description [46]. An Australian study of 84 patients with severe cutaneous adverse drug reactions found $13 \%$ patients were not given any written information of implicated medications at discharge. Moreover, $26.3 \%$ had a mismatch of knowledge regarding what they believed was the implicated medication and what was documented in hospital records [26]. Another multicentre Australian study found that nearly $30 \%$ of the anaphylaxis episodes to antimicrobials were not documented in hospital records [28]. A study in the UK showed that, of 127 general practitioners who followed up patients with ADRs after discharge, $89 \%$ had no record of patients' ADRs, having to rely on the patients themselves to provide this information [47].

Ultimately, risk communication of ADRs to patients and colleagues by HCPs remains suboptimal. Risk communication practices thus need to be incorporated in the ADR management processes as a key component to further improve patient safety and quality of care.

\section{Sources of variation}

Many studies have examined the reasons behind underreporting, yet few studies have evaluated variations in the quality of ADR reports, and risk communication. The latter two factors are more likely influenced by HCPs' knowledge and skills [48]. Thus, overall clinical competency may significantly contribute to variations in management observed [49].

\section{Behaviours and attitudes in under-reporting}

Reasons for suboptimal reporting rates have been extensively evaluated and can be grouped into several behavioural and attitudinal factors, as outlined in Table $2[20,50]$. A systematic review of 50 studies by Lopez-Gonzales et al. found that attitudes most frequently associated with under-reporting were ignorance $(95 \%)$, diffidence $(72 \%)$, lethargy $(77 \%)$, indifference and insecurity (67\%), complacency (47\%) and fear (24\%) [20]. Other barriers such as lack of training, infrequent experience with ADRs in practice, unfamiliarity with reporting requirements, lack of time, difficulties locating and completing reporting forms and bureaucratic hurdles were also identified in several studies amongst both undergraduate students and HCPs of various disciplines [51-53]. Reasons for under-reporting amongst physicians included the ADR was already well-known (75.6\%), too trivial (71.1\%) and uncertain causality (66.3\%) [54]. Conversely, ADRs with the highest probability of being reported were serious unknown adverse reactions to a new $(81.1 \%)$ or to an established medication (72.9\%), and serious known reactions to a new medication (65.2\%) [54].

\section{Knowledge gaps in ADR assessment and reporting}

Several studies have examined the impact of knowledge gaps, and the need for ADR education as a method of quality improvement.

A systematic review by Reumerman et al. found that most undergraduate medical and pharmacy students felt training was inadequate and their knowledge was insufficient in ADR reporting and pharmacovigilance activities. Prior training in ADR reporting was associated with significantly higher knowledge scores, which correlated with better skills in reporting [55]. Similarly, another systematic review evaluating essential prescribing competencies of final
Table 2 Knowledge and attitudes of healthcare professionals contributing towards under-reporting of adverse drug reactions [20]
1. Complacency - belief that only safe drugs are allowed in the market

2. Fear of possible involvement with litigation or investigation

3. Guilt at having administered treatment that may have harmed a patient

4. Ambition to compile and publish a personal case series

5. Ignorance of the requirements of reporting

6. Diffidence at reporting merely suspected ADRs

7. Indifference to essential role as clinician who should be contributing to medical knowledge

8. Lethargy - a combination of procrastination, lack of interest or time

9. Financial incentives to report

10. Insecurity - that it is nearly impossible to determine whether or not a drug is responsible for a particular ADR

$A D R$ adverse drug reaction 
year medical students found that students lacked knowledge of where and how to report ADRs, with little to no training included in undergraduate curricula [56]. Specifically in the Australian context, in a study of community pharmacists, the median score for knowledge of pharmacovigilance systems and reporting requirements was found to be just five out of a possible ten [57]. In the same survey, over $95 \%$ believed pharmacovigilance teaching should be included in the undergraduate pharmacy curriculum and almost $90 \%$ believed that professional bodies should include this topic in postgraduate professional development activities [57].

Specifically on the knowledge regarding drug hypersensitivity reactions (DHRs), an Australian multicentre study amongst 238 medical doctors and pharmacists surveyed in hospital settings found significant knowledge gaps in the domains of syndromic recognition, causality attribution, antibiotic cross-reactivity patterns and diagnostics/therapy, corresponding to an overall correct score of just 55.6\% [48]. Knowledge gaps were similar for key ADR principles assessed, regardless of healthcare profession and seniority level [48]. A lack of medication allergy knowledge in undergraduate medical training was noted in a study from Turkey, which found only $58.5 \%$ of questions regarding medication allergy were answered correctly [58].

Collectively, the above studies highlighted that many HCPs received inadequate education and training on several aspects of ADR management and pharmacovigilance in both undergraduate and postgraduate settings, even though these activities form an essential part of HCPs' professional responsibilities.

\section{ADR education as quality improvement}

The process of ADR assessment and reporting can be complex. Regardless of reporter's vocation, a comprehensive ADR evaluation requires several technical skills including knowledge and familiarity with medications, their side effect profiles and, to some extent, pharmacokinetic and pharmacodynamic properties [5]. Equally important is having knowledge of ADR patterns/syndromes and pathophysiology. Knowledge of causality attribution based on temporality, awareness of available and validated causality assessment tools, their strengths and limitations and knowledge of cross-reactivity between medication classes are also important [48]. Where causality remains unclear, awareness of available diagnostic tests for further evaluation is helpful. As spontaneous reporting relies heavily on reporters being aware of reportable ADRs, HCPs should have basic knowledge and familiarity with key concepts and requirements. Therefore, dedicated ADR education should be a key strategy to improve the quality of ADR management.

\section{ADR education curriculum}

To standardise pharmacovigilance and ADR teaching within tertiary education framework, the Netherlands Pharmacovigilance Centre, on behalf of the World Health Organization, discussed the development of university curricula at a stakeholders' meeting in 2016. The meeting identified desired competencies to be taught at the tertiary level, either integrated in existing health science courses or as a stand-alone programme [51]. The proposed curriculum is based on five key aspects: understanding the importance of pharmacovigilance, preventing ADRs, recognising ADRs, managing ADRs and reporting ADRs. It also outlines required knowledge, skills, attitudes and examples of teaching methods to achieve these aims through active learning [51]. Pharmacovigilance and ADR management aspects are incorporated into existing pharmacology education programmes. The curriculum has a healthcare-focused approach, rather than a regulatory focus, to promote patient safety, safe prescribing and reducing medication-related harm.

Complementing these WHO curricular recommendations, Herrera-Comoglio further proposed basic and advanced ADR education contents to be taught in both undergraduate and postgraduate settings (Table 3) [59].

\section{Methods of delivery}

Beyond the undergraduate curricula, periodic pharmacovigilance and ADR training should also form a mandatory part of continuing education for HCPs in their respective professional practice [60]. Such education sessions may be conducted by individual health services, universities or professional societies as part of continual professional development programmes. Indeed, the Australian Commission on Safety and Quality in Healthcare (ACSQH) 'Medication Safety Standard' stipulates orientation and training of new clinicians/practitioners to the existing ADR management systems and also that periodic competency assessments should also be provided by the healthcare institutions, including hospitals [61]. ACSQH further recommends that training must account for common medication incidents, differing levels of knowledge and experience of HCPs and accessibility to evidence-based resources and guidelines.

Contemporary healthcare education evidence suggests that ad hoc clinical exposures are insufficient to establish clinical competency and that more deliberate repeated practice opportunities achieve a deeper level of mastery $[62,63]$.

Simulation-based medical education (SBME) permits health professionals to engage in deliberate practice in a safe, learner-centred environment [64]. SBME can be a powerful education method when coupled with directed learning outcomes, structured feedback and competency assessments 
Table 3 Topics and content of adverse drug reaction education curriculum [59]

\begin{tabular}{|c|c|}
\hline Topics & Content \\
\hline Basic ADR principles & $\begin{array}{l}\text { Definitions } \\
\text { Epidemiology } \\
\text { Population impact } \\
\text { Classification } \\
\text { Identification of common ADRs }\end{array}$ \\
\hline $\begin{array}{l}\text { Knowledge of } \\
\text { hypersensitivity reactions }\end{array}$ & $\begin{array}{l}\text { Gell-Coombs classification of underlying pathophysiology } \\
\text { Clinical syndrome recognition }\end{array}$ \\
\hline Pharmacogenetics & $\begin{array}{l}\text { Definitions and concepts } \\
\text { Pharmacogenetics influencing pharmacokinetics and pharmacodynamics mechanisms and pathogenesis of } \\
\text { hypersensitivity reactions } \\
\text { Concept of personalised medicine }\end{array}$ \\
\hline Causality assessment & $\begin{array}{l}\text { Medication history and timeline } \\
\text { Clinical indications and differential diagnoses } \\
\text { Recording and assessment of past ADRs } \\
\text { Available causality assessment algorithms (e.g. Naranjo, ALDEN, Regi-SCAR, etc.), their strengths and limitations }\end{array}$ \\
\hline ADR prevention & $\begin{array}{l}\text { Therapeutic decision making } \\
\text { Knowledge of medication cross-reactivity patterns } \\
\text { Harm minimisation in prescribing (e.g. dose adjustment, avoidance) } \\
\text { Effective risk communication to patients and other healthcare professionals }\end{array}$ \\
\hline ADR reporting & $\begin{array}{l}\text { Reliable sources of information (regulatory information, WHO, LiverTox etc) } \\
\text { Knowledge of pharmacovigilance systems, reporting requirements and processes } \\
\text { Compiling a comprehensive high-quality report }\end{array}$ \\
\hline
\end{tabular}

$A D R$ adverse drug reaction, $A L D E N$ Algorithm for Assessment of Drug Causality in Stevens-Johnson Syndrome and Toxic Epidermal Necrolysis, Regi-SCAR Registry of Severe Cutaneous Adverse Reaction, WHO World Health Organization

sequenced at progressive levels of difficulty [64-66]. SBME has been used to establish competency in a range of skills (e.g. decision-making, communication) within a variety of healthcare professions including medicine and pharmacy [64]. Simulated clinician-patient interactive communication sessions for final year medical students centred on medication errors and adverse drug events received very high acceptance rates and improved awareness of knowledge deficits amongst students [67].

In contrast, a literature review of pharmacovigilance education in HCPs suggests that learners prefer deliberate experiential learning using realistic cases rather than simulated scenarios [55]. Other education interventions that can support ADR recognition, management and reporting include problem-based learning and team-based learning especially when incorporated into interprofessional activities amongst HCPs [68]. Whilst there is no definitive answer as to the most effective method of education delivery, the strategies mentioned all rely on the learner's active retrieval and application of knowledge and skills. This is consistent with evidence suggesting that active learning (e.g. SBME, experiential learning) has a greater impact on knowledge, attitudes and skills than passive learner (e.g. didactic lectures) [69].

\section{Evidence regarding education interventions and ADR outcomes}

Studies have shown that brief education interventions, either stand-alone or in combination with other measures, improve the rate of ADR reporting. A systematic review by $\mathrm{Li}$ et al. evaluated multiple strategies in hospital and primary care settings targeted at improving ADR reporting rates [70]. The most common strategies employed were educational sessions, including group presentations or workshops (31.6\%) and systemic changes, such as electronic ADR reporting tools (26.3\%). Other initiatives included reminders (15.8\%), offering an economic incentive $(10.5 \%)$, utilising telephone interventions $(10.5 \%)$ and providing feedback to reporters (5.3\%). All interventions increased both the rate and number of ADR reports. The point estimate increase in reporting rates was 9.26 -fold (95\% CI: -2.21 to 20.74 ) for multifaceted approaches and 7.19-fold (95\% CI: -2.73 to 17.11) for single interventions. Traditional education methods alone increased reporting rates by 4.42 -fold (95\% CI: 0.66-8.19). Electronic reporting tools served as passive facilitators, whilst education sessions and/or reminders proved active promoters of ADR reporting. 
A systematic review by Pagotto et al. also found positive impacts in spontaneous reporting practices with education interventions [60]. The studies included in this review adopted multiple interventions, which included distribution of printed educational materials, repeated email reminders, educational lectures, workshops, group dynamic exercises, regular meetings, outreach visits and interviews or questionnaires to reporters [60]. In a cluster randomised controlled trial by Lopez-Gonzalez et al., education was delivered through group sessions and educational materials with particular focus on the importance of ADR reporting, by emphasising ADR-associated morbidity, mortality and cost data, as well as the limitations of clinical trials for pharmacovigilance measures, hence the importance of spontaneous reporting as a post-marketing pharmacovigilance tool. Education intervention improved total ADR reports by 1.65 -fold (95\% CI: $1.08-2.53$ ), serious ADRs by $1.62-$ fold (95\% CI: 0.99-2.65), unexpected ADRs by 2.06 (95\% CI: $1.19-3.55)$ and high causality ADRs by 1.13 (95\% CI: $0.72-1.77)$ over the 8-month follow-up period. However, improvement efforts did not sustain beyond 4 months with a single education session [71].

Education, in the form of outreach visits, has also been shown to improve overall ADR reporting rates (RR 10.23, 95\% CI 3.81-27.51) and that of serious, high causality, unexpected and new-drug-related ADRs in a cluster randomised controlled trial conducted in Portugal. The outreach visits included presentation of data on ADR-related morbidity and mortality, rate of hospital admission, cost to patients and the health system and information on pharmacovigilance systems. The presentation also addressed the attitudes associated with under-reporting. However, the improvement was also found to be maximal in the first 4 months and waned over time [72].

Although brief educational interventions have been shown to improve ADR reporting rates, pooled results from single forms of education only achieved a modest 2.3 -fold increase in rates $[42,71]$. In contrast, combining education with reminders, feedback and improved accessibility to reporting resources resulted in a 14-fold increase in reporting [73]. Also, single education sessions rarely provide sustained improvement over time, thus emphasising the importance of repeated reinforcement $[71,72]$.

Whilst many studies have shown that education strategies can improve overall ADR reporting rates, no studies to date have specifically evaluated the impact of educational interventions on the quality of ADR assessment and reporting, as well as on risk communication and patient safety. Education strategies that focus on the latter quality outcomes are urgently needed.

\section{Summary and future directions}

In hospital settings, spontaneous reporting remains the main method of detecting and monitoring ADRs. Whilst the primary purpose is to contribute toward pharmacovigilance and centralised regulatory activities, the local focus of ADR management should be to promote patient safety through comprehensive assessment, risk communication and safe prescribing.

Hospital ADR management processes vary greatly, from having only individual reporters to a multi-disciplinary ADR review committee, depending on the size of the institution and resources available. Complexity of ADRs encountered also varies, depending on the patient population and specialty services available. Human factors, such as HCP expertise, attitudes and knowledge, affect assessment and reporting practices. Quantitative outcomes, such as the number of ADR reports, can be easily monitored. However, available and practical tools to measure the quality of ADR management remain ill-defined. Certain indicators, such as completeness of ADR reports, which reflect the quality of assessment, and frequency and effectiveness of risk communication practices, need to be monitored for an indication of overall quality of ADR management at an individual healthcare organisation level. Further research is needed to develop validated and easy-to-use tools that can be utilised within hospital environments to measure and quantify quality indicators.

Whilst systemic approaches such as development ADR reporting guidelines, standardisation of reporting forms or electronic reminders/prompts may help improve spontaneous reporting rates, it is still important to address the gaps in knowledge and competency of HCPs in ADR assessment as a quality improvement process. Robust ADR and pharmacovigilance education programmes at both undergraduate and postgraduate levels may bridge some of these identified gaps. Education processes need to be relevant and targeted at appropriate profession and skill levels and reinforced at intermittent intervals for improvements to be sustained. Outcomes of educational interventions should be systematically measured, preferably through quality indicators, and regularly reported.

Acknowledgements We thank Dr Daniel mazzoni and Dr Tess Aitken for their perspectives and contributions to improve the quality and content of this manuscript.

Author contribution Conceptualisation: Ar Kar Aung, Linda Velta Graudins, Steven Walker, Jennifer Inhae Lee, Yin Li Khu and Mei Jie Tang; literature search and data analysis: Ar Kar Aung, Linda Velta Graudins and Steven Walker; drafting: Ar Kar Aung, Linda Velta Graudins and Steven Walker; critical revision: Jennifer Inhae Lee, Yin Li Khu and Mei Jie Tang. 
Funding Open Access funding enabled and organized by CAUL and its Member Institutions.

\section{Declarations}

\section{Ethics approval N/A.}

Consent to participate N/A.

\section{Consent for publication N/A.}

Conflict of interest The authors declare no competing interests.

Open Access This article is licensed under a Creative Commons Attribution 4.0 International License, which permits use, sharing, adaptation, distribution and reproduction in any medium or format, as long as you give appropriate credit to the original author(s) and the source, provide a link to the Creative Commons licence, and indicate if changes were made. The images or other third party material in this article are included in the article's Creative Commons licence, unless indicated otherwise in a credit line to the material. If material is not included in the article's Creative Commons licence and your intended use is not permitted by statutory regulation or exceeds the permitted use, you will need to obtain permission directly from the copyright holder. To view a copy of this licence, visit http://creativecommons.org/licenses/by/4.0/.

\section{References}

1. Australian Government, Department of Health, Therapeutic Goods Administration (2019) Reporting adverse events. [cited 2020 Nov 30]; Available from: https://www.tga.gov.au/reportingadverse-events

2. Thien FCK (2006) 3. Drug hypersensitivity. Med J Aust 01 Sept 2006 185(6):333-338

3. Wolfe D, Yazdi F, Kanji S, Burry L, Beck A, Butler C et al (2018) Incidence, causes, and consequences of preventable adverse drug reactions occurring in inpatients: a systematic review of systematic reviews. PloS One 13(10):e0205426

4. Organization WH(2019) Medication safety curriculum guide. [cited 2020 Nov 20]; Available from: https://www.pharmacologyeducation.org/ sites/default/files/WHO\%20Medication\%20Safety\%20Curriculum\% 20Guide\%202019.pdf

5. Organisation WH (2002) Safety of medicines - a guide to detecting and reporting adverse drug reactions - why health professionals need to take action

6. Bouvy JC, De Bruin ML, Koopmanschap MA (2015) Epidemiology of adverse drug reactions in Europe: a review of recent observational studies. Drug Saf 38(5):437-453

7. Impicciatore $\mathrm{P}$, Choonara I, Clarkson A, Provasi D, Pandolfini C, Bonati M (2001) Incidence of adverse drug reactions in paediatric in/out-patients: a systematic review and meta-analysis of prospective studies. Br J Clin Pharmacol 52(1):77-83

8. Sultana J, Cutroneo P, Trifirò G (2013) Clinical and economic burden of adverse drug reactions. J Pharmacol Pharmacother 4(Suppl 1):S73-S77

9. Roughead EE, Semple SJ, Rosenfeld E (2016) The extent of medication errors and adverse drug reactions throughout the patient journey in acute care in Australia. Int $\mathbf{J}$ Evid Based Healthc 14(3-4):113-122

10. Miguel A, Azevedo LF, Araújo M, Pereira AC (2012) Frequency of adverse drug reactions in hospitalized patients: a system- atic review and meta-analysis. Pharmacoepidemiol Drug Saf 21(11):1139-1154

11. Nair NP, Chalmers L, Bereznicki BJ, Curtain CM, Bereznicki LR (2017) Repeat adverse drug reaction-related hospital admissions in elderly Australians: a retrospective study at the Royal Hobart Hospital. Drugs Aging 34(10):777-783

12. Davies EC, Green CF, Taylor S, Williamson PR, Mottram DR, Pirmohamed M (2009) Adverse drug reactions in hospital inpatients: a prospective analysis of 3695 patient-episodes. PLoS One 4(2):e4439

13. Baiardini I, Gaeta F, Molinengo G, Braido F, Canonica GW, Romano A (2015) Quality-of-life issues in survivors to anaphylactic reactions to drugs. Allergy $01 \mathrm{Jul} 2015$ 70(7):877-879

14. Lorimer S, Cox A, Langford N (2011) A patient's perspective: the impact of adverse drug reactions on patients and their views on reporting. J Clin Pharm Ther 18 May 2011 37:148-152

15. Caplan LR (2001) Evidence based medicine: concerns of a clinical neurologist. J Neurol Neurosurg Psychiatry 71(5):569

16. Van Grootheest A, Van Puijenbroek E, de Jong-van den Berg L (2002) Contribution of pharmacists to the reporting of adverse drug reactions. Pharmacoepidemiol Drug Saf 11(3):205-210

17. Gedde-Dahl A, Harg P, Stenberg-Nilsen H, Buajordet M, Granas AG, Horn AM (2007) Characteristics and quality of adverse drug reaction reports by pharmacists in Norway. Pharmacoepidemiol Drug Saf 16(9):999-1005

18. Aagaard L, Hansen EH (2009) Information about ADRs explored by pharmacovigilance approaches: a qualitative review of studies on antibiotics SSRIs and NSAIDs. BMC Clin Pharmacol $9(1): 1-14$

19. Department of Health TGA (2020) Reporting adverse events. [cited 20206 Nov]; Available from: https://www.tga.gov.au/reportingadverse-events

20. Lopez-Gonzalez E, Herdeiro MT, Figueiras A (2009) Determinants of under-reporting of adverse drug reactions. Drug Saf 32(1):19-31

21. Aung AK, Tang MJ, Adler NR, de Menezes SL, Goh MSY, Tee HW et al (2018) Adverse drug reactions reported by healthcare professionals: reaction characteristics and time to reporting. J Clin Pharmacol 58(10):1332-1339

22. Bergvall T, Norén GN, Lindquist M (2014) vigiGrade: a tool to identify well-documented individual case reports and highlight systematic data quality issues. Drug Saf 37(1):65-77

23. Rawlins MD (1995) Pharmacovigilance: paradise lost, regained or postponed?: the William Withering lecture 1994. J R Coll Physicians Lond 29(1):41

24. Hazell L, Shakir SA (2006) Under-reporting of adverse drug reactions. Drug Saf 29(5):385-96

25. Mittmann N, Knowles SR, Gomez M, Fish JS, Cartotto R, Shear NH (2004) Evaluation of the extent of under-reporting of serious adverse drug reactions. Drug Saf 27(7):477-487

26. Graudins LV, Ly J, Trubiano J, Aung AK (2016) More than skin deep. Ten year follow-up of delayed cutaneous adverse drug reactions (CADR). Br J Clin Pharmacol 82(4):1040-1047

27. Graudins LV, Trubiano JA, Zubrinich CM, Elliott AS, Aung AK (2018) Medication-related anaphylaxis treated in hospital: agents implicated, patient outcomes, and management lessons. Pharmacoepidemiol Drug Saf 27(9):1029-1033

28. Hall V, Wong M, Munsif M, Stevenson BR, Elliott K, Lucas $M$ et al (2020) Antimicrobial anaphylaxis: the changing face of severe antimicrobial allergy. J Antimicrob Chemother 75(1):229-235

29. Naranjo CA, Busto U, Sellers EM, Sandor P, Ruiz I, Roberts E et al (1981) A method for estimating the probability of adverse drug reactions. Clin Pharmacol Ther 30(2):239-245

30. Sassolas B, Haddad C, Mockenhaupt M, Dunant A, Liss Y, Bork $\mathrm{K}$ et al (2010) ALDEN, an Algorithm for Assessment of Drug Causality in Stevens-Johnson Syndrome and Toxic Epidermal 
Necrolysis: comparison with case-control analysis. Clin Pharmacol Therapeut 88(1):60-68

31. Kardaun S, Sekula P, Valeyrie-Allanore L, Liss Y, Chu C, Creamer D et al (2013) Drug reaction with eosinophilia and systemic symptoms (DRESS): an original multisystem adverse drug reaction. Results from the prospective R egi SCAR study. Br J Dermatol 169(5):1071-1080

32. Smyth RL, Peak M, Turner MA, Nunn AJ, Williamson PR, Young B et al (2015) ADRIC: adverse drug reactions in children-a programme of research using mixed methods

33. Bandekar M, Anwikar S, Kshirsagar N (2010) Quality check of spontaneous adverse drug reaction reporting forms of different countries. Pharmacoepidemiology Drug Saf 19(11):1181-1185

34. Onakpoya IJ, Heneghan CJ, Aronson JK (2016) Post-marketing withdrawal of 462 medicinal products because of adverse drug reactions: a systematic review of the world literature. BMC Med 14(1): 10

35. Plessis L, Gómez A, García N, Cereza G, Figueras A (2017) Lack of essential information in spontaneous reports of adverse drug reactions in Catalonia - a restraint to the potentiality for signal detection. Eur J Clin Pharmacol 73(6):751-758

36. Fernandez-Fernandez C, Lázaro-Bengoa E, Fernández-Antón2 E, Quiroga-González L, Corominas DM (2020) Quantity is not enough: completeness of suspected adverse drug reaction reports in Spaindifferences between regional pharmacovigilance centres and pharmaceutical industry. Eur J Clin Pharmacol 76:1175-1181

37. Tsuchiya M, Obara T, Miyazaki M, Noda A, Takamura C, Mano N (2020) The quality assessment of the Japanese adverse drug event report database using vigiGrade. Int J Clin Pharm 1-9

38. Chen Y, Niu R, Xiang Y, Wang N, Bai J, Feng B (2019) The quality of spontaneous adverse drug reaction reports in china: a descriptive study. Biol Pharm Bull 42(12):2083-2088

39. Niu R, Xiang Y, Wu T, Zhang Z, Chen Y, Feng B (2019) The quality of spontaneous adverse drug reaction reports from the pharmacovigilance centre in western China. Expert Opin Drug Saf 18(1):51-58

40. Ribeiro A, Lima S, Zampieri M-E, Peinado M, Figueras A (2017) Filling quality of the reports of adverse drug reactions received at the Pharmacovigilance Centre of São Paulo (Brazil): missing information hinders the analysis of suspected associations. Expert Opin Drug Saf 16(12):1329-1334

41. Durrieu G, Jacquot J, Mège M, Bondon-Guitton E, Rousseau V, Montastruc F et al (2016) Completeness of spontaneous adverse drug reaction reports sent by general practitioners to a regional pharmacovigilance centre: a descriptive study. Drug Saf 39(12):1189-1195

42. Johansson M-L, Hägg S, Wallerstedt SM (2011) Impact of information letters on the reporting rate of adverse drug reactions and the quality of the reports: a randomized controlled study. BMC Clin Pharmacol 11(1):14

43. Rolfes L, van Hunsel F, van der Linden L, Taxis K, van Puijenbroek $\mathrm{E}$ (2017) The quality of clinical information in adverse drug reaction reports by patients and healthcare professionals: a retrospective comparative analysis. Drug Saf 40(7):607-614

44. Mahajan MM, Thatte UM, Gogtay NJ, Deshpande S (2018) An analysis of completeness and quality of adverse drug reaction reports at an adverse drug reaction monitoring centre in Western India. Perspect Clin Res 9(3):123

45. Adler N, Graudins L, Aung AK (2017) The importance of risk communication and documentation for patients with cutaneous adverse drug reactions. Br J Dermatol 177(5):1461

46. Teo Y, Walsh S, Creamer D (2017) Cutaneous adverse drug reaction referrals to a liaison dermatology service. Br J Dermatol 177(4):e141

47. Green C, Mottram D, Pirmohamed M, Horner R, Rowe P (1999) Communication regarding adverse drug reactions between sec- ondary and primary care: a postal questionnaire survey of general practitioners. J Clin Pharm Ther 24(2):133-139

48. Mazzoni D, Tee HW, de Menezes SL, Graudins LV, Johnson DF, Newnham ED et al (2020) A survey on knowledge gaps in assessment and management of severe drug hypersensitivity reactions: multicenter cross-sectional study of Australian health care providers. J Clin Pharmacol

49. FitzGerald RJ (2009) Medication errors: the importance of an accurate drug history. Br J Clin Pharmacol 67(6):671-675

50. Inman W (1996) Attitudes to adverse drug reaction reporting. Br J Clin Pharmacol 41(5):434

51. van Eekeren R, Rolfes L, Koster AS, Magro L, Parthasarathi G, Al Ramimmy H et al (2018) What future healthcare professionals need to know about pharmacovigilance: introduction of the WHO PV core curriculum for university teaching with focus on clinical aspects. Drug Saf 41(11):1003-1011

52. Kopciuch D, Zaprutko T, Paczkowska A, Ratajczak P, ZielińskaTomczak $€$, Kus K et al (2019) Safety of medicines-pharmacists' knowledge, practice, and attitudes toward pharmacovigilance and adverse drug reactions reporting process. Pharmacoepidemiol Drug Saf 28(12):1543-1551

53. Hughes ML, Weiss M (2019) Adverse drug reaction reporting by community pharmacists - the barriers and facilitators. Pharmacoepidemiol Drug Saf 28(12):1552-1559

54. Hasford J, Goettler M, Munter K-H, Müller-Oerlinghausen B (2002) Physicians' knowledge and attitudes regarding the spontaneous reporting system for adverse drug reactions. J Clin Epidemiol 55(9):945-950

55. Reumerman M, Tichelaar J, Piersma B, Richir M, van Agtmael M (2018) Urgent need to modernize pharmacovigilance education in healthcare curricula: review of the literature. Eur J Clin Pharmacol 74(10):1235-1248

56. Brinkman DJ, Tichelaar J, Graaf S, Otten RH, Richir MC, van Agtmael MA (2018) Do final-year medical students have sufficient prescribing competencies? A systematic literature review. Br J Clin Pharmacol 84(4):615-635

57. Li R, Curtain C, Bereznicki L, Zaidi STR (2018) Community pharmacists' knowledge and perspectives of reporting adverse drug reactions in Australia: a cross-sectional survey. Int J Clin Pharm 40(4):878-889

58. Özdemir PG, Kızılca Ö, Aylanç H, Çelik V, Beken B, Akbulut SD et al (2020) Residents and interns in the 3 university hospitals: their knowledge of and attitudes to drug allergy. Asia Pac Allergy $10(3)$

59. Herrera Comoglio R (2020) Undergraduate and postgraduate pharmacovigilance education: a proposal for appropriate curriculum content. Br J Clin Pharmacol 86(4):779-790

60. Pagotto C, Varallo F, Mastroianni P (2013) Impact of educational interventions on adverse drug events reporting. Int $\mathrm{J}$ Technol Assess Health Care 29(4):410

61. Australian Commission on Safety and Quality in Health Care (2020) Clinical governance and quality improvement to support medication management. The national safety and quality health service standards [cited 2020 November 30]; Available from: https://www.safetyandquality.gov.au/standards/nsqhsstandards/medication-safety-standard/clinical-governance-andquality-improvement-support-medication-management/action-41

62. Friedman Z, Siddiqui N, Katznelson R, Devito I, Davies S (2008) Experience is not enough: repeated breaches in epidural anesthesia aseptic technique by novice operators despite improved skill. J Am Soc Anesthesiol 108(5):914-920

63. McGaghie WC, Issenberg SB, Cohen ER, Barsuk JH, Wayne DB (2011) Medical education featuring mastery learning with deliberate practice can lead to better health for individuals and populations. Acad Med 86(11):e8-e9 
64. Motola I, Devine LA, Chung HS, Sullivan JE, Issenberg SB (2013) Simulation in healthcare education: a best evidence practical guide. AMEE Guide No. 82. Med Teach 35(10):e1511-e1530

65. Ziv A, Ben-David S, Ziv M (2005) Simulation based medical education: an opportunity to learn from errors. Med Teach 27(3):193-199

66. Wang CL, Chinnugounder S, Hippe DS, Zaidi S, O'Malley RB, Bhargava $P$ et al (2017) Comparative effectiveness of hands-on versus computer simulation-based training for contrast media reactions and teamwork skills. J Am Coll Radiol 14(1):103-110 e3

67. Kirsch V, Johannsen W, Thrien C, Herzig S, Matthes J (2019) Hopefully, I will never forget that again-sensitizing medical students for drug safety by working on cases and simulating doctorpatient communication. GMS J Med Educ 36(2)

68. Achike FI, Smith J, Leonard S, Williams J, Browning F, Glisson J (2014) Advancing safe drug use through interprofessional learning (IPL): a pilot study. J Clin Pharmacol 54(7):832-839

69. Freeman S, Eddy SL, McDonough M, Smith MK, Okoroafor N, Jordt $\mathrm{H}$ et al (2014) Active learning increases student performance in science, engineering, and mathematics. Proc Natl Acad Sci 111(23):8410-8415
70. Li R, Zaidi STR, Chen T, Castelino R (2020) Effectiveness of interventions to improve adverse drug reaction reporting by healthcare professionals over the last decade: a systematic review. Pharmacoepidemiol Drug Saf 29(1):1-8

71. Lopez-Gonzalez E, Herdeiro MT, Piñeiro-Lamas M, Figueiras A (2015) Effect of an educational intervention to improve adverse drug reaction reporting in physicians: a cluster randomized controlled trial. Drug Saf 38(2):189-196

72. Figueiras A, Herdeiro MT, Polónia J, Gestal-Otero JJ (2006) An educational intervention to improve physician reporting of adverse drug reactions: a cluster-randomized controlled trial. Jama 296(9):1086-1093

73. Ríos OM, Gutiérrez LJ, Talavera JO, Téllez-Rojo MM, López VO, Espinosa JG et al (2016) A comprehensive intervention for adverse drug reactions identification and reporting in a pediatric emergency department. Int J Clin Pharmacol 38(1):80-87

Publisher's Note Springer Nature remains neutral with regard to jurisdictional claims in published maps and institutional affiliations. 